\title{
Gastrointestinal parasites of canids, a latent risk to human health in Tunisia
}

\author{
Myriam Oudni-M'rad ${ }^{1 *}$, Raja Chaâbane-Banaoues ${ }^{1}$, Selim M'rad ${ }^{1}$, Fatma Trifa2 ${ }^{2}$, Habib Mezhoud ${ }^{1}$ \\ and Hamouda Babba ${ }^{1,3}$
}

\begin{abstract}
Background: Although data on the parasite environmental contamination are crucial to implement strategies for control and treatment, information about zoonotic helminths is very limited in Tunisia. Contamination of areas with canid faeces harboring infective parasite elements represents a relevant health-risk impact for humans. The aim of this study was to assess the environmental contamination with eggs and oocysts of gastrointestinal parasites of dogs and wild canids in Tunisia with special attention to those that can be transmitted to humans.

Results: One thousand two hundred and seventy faecal samples from stray dogs and 104 from wild canids (red foxes and golden jackals) were collected from different geographical regions throughout Tunisia. The helminth eggs and protozoan oocysts were concentrated by sucrose flotation and identified by microscopic examination. The most frequently observed parasites in dog samples were Toxocara spp. (27.2\%), E. granulosus (25.8\%), and Coccidia (13.1\%). For wild canid faeces, the most commonly encountered parasites were Toxocara spp. (16.3\%) followed by Capillaria spp. (9.6\%). The parasite contamination of dog faeces varied significantly from one region to another in function of the climate.
\end{abstract}

Conclusion: To our knowledge, the study highlights for the first time in Tunisia a serious environmental contamination by numerous parasitic stages infective to humans. Efforts should be made to increase the awareness of the contamination risk of such parasites in the environment and implement a targeted educational program.

Keywords: Gastrointestinal parasites, Environmental parasite contamination, Zoonosis, Tunisia, Canids

\section{Background}

Parasitic infections are among the most common infections worldwide, principally in developing countries with poor environmental sanitation and inadequate personal hygiene. In particular, soil-transmitted helminths (Ascaris lumbricoides, whipworm (Trichuris trichiura) and hookworm) causing the "neglected infections of poverty" have a relevant health-risk impact on humans and animals [1-5]. Nevertheless, gastrointestinal parasites of canids constitute another source of human and livestock infection mainly due to environmental contamination with faeces containing infective parasitic forms (eggs, larvae or oocysts) [6-8]. Several serious parasitic diseases transmitted by dogs, such as hydatidosis and toxocariasis, are regarded as serious public health problems especially in

\footnotetext{
* Correspondence: myriam.mrad@gnet.tn

${ }^{1}$ Laboratory of Medical and Molecular Parasitology-Mycology (LP3M), LR 12ES08. Faculty of Pharmacy, University of Monastir, 5000 Monastir, Tunisia Full list of author information is available at the end of the article
}

Mediterranean countries [9-11]. Wild canids are also the reservoir of a wide range of parasites including parasites that are shared between pets and humans [12-14]. Human infections are acquired via the ingestion of eggs or oocysts via contaminated foodstuffs or water, hands, inhalation of dust, and/or by penetration of larvae through the skin [15]. Geophagia (eating of earth) and shoeless walking are the most common risk factors of contamination in children $[16,17]$.

In Tunisia, the canine population is estimated at 800,000 dogs and is essentially composed of stray and semi-stray (free-roaming dogs which are fed by an owner) dogs that rarely receive deworming treatment [18]. The uncontrolled displacement of canids in rural and urban areas increases the contamination risk of the soil, food and water with parasitic elements. The dog faeces are not removed from the ground and may be a serious hazard for human health. Epidemiological studies have been performed on gastrointestinal 
helminths in necropsied dogs [19-21] and wild canids $[21,22]$ in Tunisia but relatively little information on the environmental contamination by protozoan oocysts or helminth eggs is currently available [23]. Thus, understanding the epidemiology of zoonotic parasitic infections due to canids is necessary to minimize the exposure risk to humans.

The aim of the present work was (i) to assess the data from an epidemiological survey of environmental contamination with helminth eggs and protozoan cysts of dogs, with special attention to those that can be transmitted to humans; and (ii) to investigate the possible role of wild canids in the transmission of gastrointestinal parasites to humans.

\section{Methods}

\section{Sample collection}

One thousand two hundred and seventy faecal samples from dogs (Canis familiaris) were collected from the soil from four climate zones in Tunisia: sub-humid (Kef), semi-arid (Kasserine, Sousse and Monastir), arid (Djerba Island, Zarzis and Metlaoui), and desertic (Douz and Tataouine) (Fig. 1). Forty samples were randomly collected from a proportion of the faeces observed over a soil surface of $200-400 \mathrm{~m}^{2}$ according to the abundance of faeces in each location. One hundred and four faeces from wild canids were isolated: 88 faecal samples around red fox burrows (Vulpes vulpes) from Djerba Island and 16 faeces from the rest sites of golden jackals (Canis aureus) from Zarzis. The samples were collected with the help of hunters and experienced forestry technicians based essentially on the defecation sites, the shape and size of faeces, and the footprints left by wild canids. All faeces were taken from rural, semi-urban, and urban sites in the vicinity of livestock breeding (ovine and bovine). Houses and animal husbandries were observed around all the study areas.

Several sites were visited for each region (2-5) and samples were collected in spring and summer. The sampling was not related to a number of individual canids, but intended to represent the available parasite eggs or oocysts in the area. Faecal samples were collected without alcohol or formalin fixation and frozen at $-80{ }^{\circ} \mathrm{C}$ for 7 days in order to partially inactivate infective stages of the parasites.

\section{Microscopic and molecular analysis}

The gastrointestinal helminth eggs and protozoan oocysts were concentrated by sucrose density gradient flotation with a specific gravity of 1.27 [24]. Slides were then systematically microscopically checked at 40x magnification. Using morphological and morphometric characteristics, each egg or

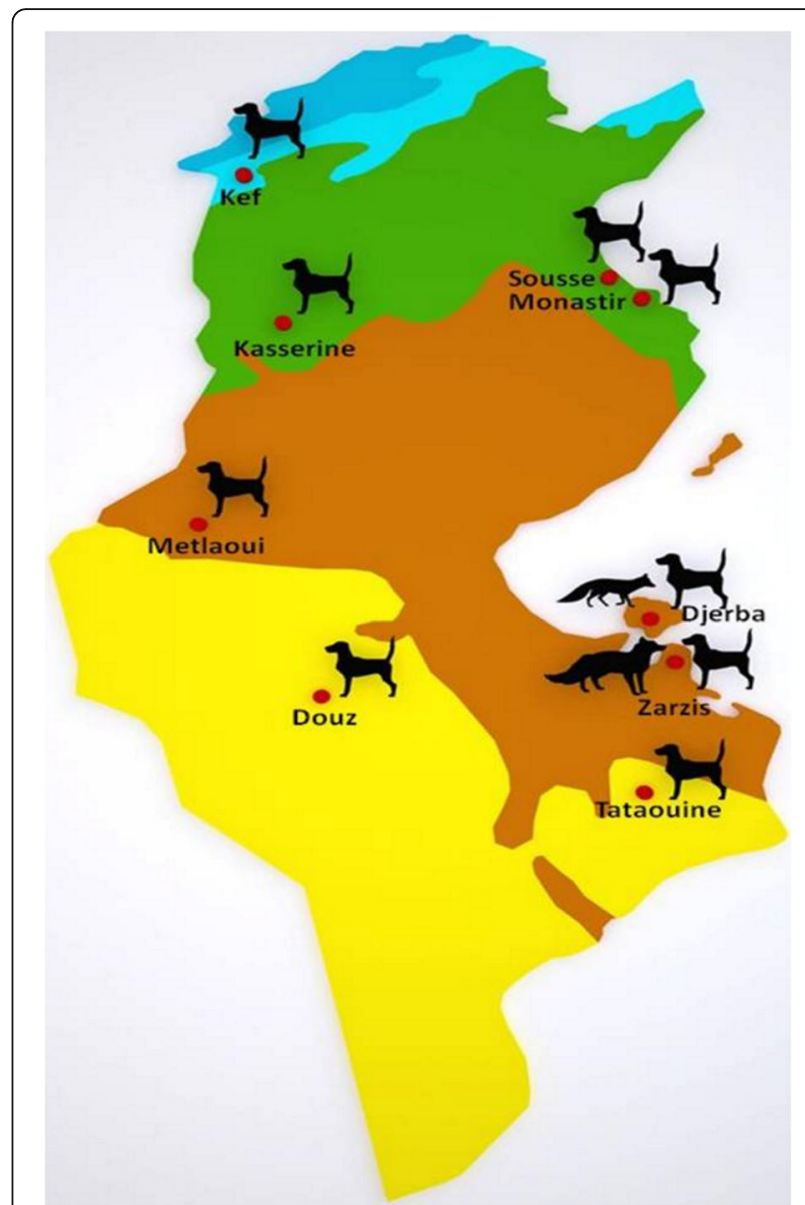

Fig. 1 Faecal sampling collections from dogs and wild canids in different Tunisian locations according to the climate: humid (blue), sub-humid (turquoise), semi-arid (green), Arid (brown), desertic (yellow)

protozoan oocyst was identified by light microscopic examination [25]. With the exception of Echinococcus granulosus and Dipylidium caninum, isolated parasites were identified at the family/genus level. Since the taeniid eggs are morphologically indistinguishable, Eg1121/1122 PCR was used to identify the E. granulosus among taeniid egg-positive samples. Briefly, an alkaline lysis using DTT (dithiothreitol) and $\mathrm{KOH}$ (potassium hydroxide) followed by an enzymatic digestion by proteinase $\mathrm{K}$ (Invitrogene, Karlsruhe, Germany) were performed to destroy the embryophore's rigid shell. The total DNA was extracted using a phenol chloroform protocol [26]. The PCR approach was realized as previously described by Chaabane-Banaoues et al. [23].

The percentage of faecal samples found positive for at least one parasitic element (egg or oocyst) provided the parasite contamination index which was estimated as the number of positive parasite isolates/total number of examined samples in each location. 


\section{Statistical analysis}

The categorical variables were expressed as percentages and the exact binomial confidence intervals were calculated $(95 \% \mathrm{CI})$. The Pearson's Chi-square and the Spearman's correlation tests were used to compare the contamination indices according to the host (wild or domestic canid), the sampling regions, and the relationship between parasites (SPSS software, version 18.0). All $P$-values less than 0.05 were considered as statistically significant.

The dog faeces contamination indices higher than $4 \%$, the temperature (annual average maximum temperature), and the rainfall (average yearly rainfall) of studied regions were compared using the principal component analysis (PCA) with MVSP software (Multivariate statistical package. MVSP. User' manual. Version 3.1. KCS, 288. Pentraeth, Wales, UK. 2002).

\section{Results}

The present study revealed the presence of numerous pathogenic helminth eggs and protozoan oocysts (Table 1 and Fig. 2). The overall contamination index was 55\% (95\% CI: 52.2-57.7) and 46.1\% (95\% CI: 36.5-55.6) for dog and wild canid faecal samples respectively. Multiple infections were less frequent (30.1\%, 95\% CI: 26.8-33.3) than single infection $(70 \%, 95 \%$ CI: $66.7-73.2)$ in $\operatorname{dog}$ faeces (from all regions). Similar results were obtained for the wild canid (Djerba-Zarzis) samples, and 38.5\% (95\% CI: 29.1-47.8) of them presented multiple infections versus $61.5 \%$ (95\% CI: $52.2-70.9)$ for single infections (data not shown).

Parasite distribution was significantly different between the dogs and wild canids in Zarzis and Djerba for E. granulosus $\left(\chi^{2}=28.95, d f=1, P<0.0001\right)$, Toxocara spp. $\left(\chi^{2}=11.63, d f=1, P=0.0006\right)$, Capillaria spp. $\left(\chi^{2}=21.25, d f=1, \quad P<0.0001\right)$ and Spirocerca $\operatorname{spp} .\left(\chi^{2}=4.95, d f=1, P=0.026\right)$ (Table 2). For the dog faeces, the most frequently observed parasites were Toxocara spp. (27.2\%), E. granulosus (25.8\%) and Coccidia (13.1\%) (Table 1). Thanks to biomolecular analysis, $94 \%$ of Taeniidae samples (328 faeces) were identified as E. granulosus eggs (Table 1). Nevertheless, it should be noted that co-infection with other species of Taeniidae cannot be excluded. The wild canids were predominately infected with Toxocara spp. (16.3\%) and Capillaria spp. (9.6\%) (Table 2). No E. granulosus egg was detected in wild canids in Djerba and Zarzis regions whereas dog faeces were largely contamined (22.6\%) (Table 2).

The parasite environmental contamination varied significantly from one region to another (Table 1). Echinococcus granulosus was predominant for the faecal samples from the arid region whereas Trichuris spp. was the most frequently observed parasite for the sub-humid area (Table 1). The other regions had a similar parasite distribution and Toxocara spp. was the most commonly parasite found. Dipylidium caninum, Spirocerca spp. and Capillaria spp. were present in dog faeces with an occurrence lower than 1\% (Table 1).

As for the dog samples, the Spearman's correlation coefficient demonstrated a positive correlation between $E$. granulosus and Toxocara spp. eggs $\left(r_{s}=0.55, P=0.132\right)$, and a negative correlation between $E$. granulosus and Trichuris spp. eggs $\left(r_{s}=-0.67, P=0.044\right)$. The PCA graphics highlighted that Trichuris spp., Ancylostoma spp., and Coccidia distributions were significantly and positively correlated with rainfall (Fig. 3, Axis 2). The E. granulosus

Table 1 Parasite contamination index of dog faeces in relation to regions and climate

\begin{tabular}{|c|c|c|c|c|c|c|c|c|c|c|c|}
\hline \multirow{2}{*}{$\begin{array}{l}\text { Climate } \\
\text { Locality }\end{array}$} & \multirow{2}{*}{$\begin{array}{l}\text { Sub-humid } \\
\begin{array}{l}\text { Kef } \\
(N=36)\end{array}\end{array}$} & \multicolumn{3}{|l|}{ Semi-arid } & \multicolumn{3}{|l|}{ Arid } & \multicolumn{2}{|l|}{ Desertic } & \multirow[b]{2}{*}{$P$-value } & \multirow{2}{*}{$\begin{array}{l}\text { Overall } \\
\text { contamination } \\
\text { index }\end{array}$} \\
\hline & & $\begin{array}{l}\text { Kasserine } \\
(N=132)\end{array}$ & $\begin{array}{l}\text { Monastir } \\
(N=95)\end{array}$ & $\begin{array}{l}\text { Sousse } \\
(N=81)\end{array}$ & $\begin{array}{l}\text { Metlaoui } \\
(N=392)\end{array}$ & $\begin{array}{l}\text { Zarzis } \\
(N=129)\end{array}$ & $\begin{array}{l}\text { Djerba } \\
(N=127)\end{array}$ & $\begin{array}{l}\text { Tataouine } \\
(N=103)\end{array}$ & $\begin{array}{l}\text { Douz } \\
(N=175)\end{array}$ & & \\
\hline Parasite & $\%(n)$ & $\%(n)$ & $\%(n)$ & $\%(n)$ & $\%(n)$ & $\%(n)$ & $\%(n)$ & $\%(n)$ & $\%(n)$ & & \\
\hline Toxocara spp. & $16.7(6)$ & $17.4(23)$ & $30.5(29)$ & $17.3(14)$ & $29.3(115)$ & $17.8(23)$ & $51.2(65)$ & $21.3(22)$ & $26.8(47)$ & $<0.00001$ & $27.2(344)$ \\
\hline Taeniidae & $8.3(3)$ & $18.9(25)$ & $10.5(10)$ & $13.6(11)$ & 44.6 (175) & $17.8(23)$ & $29.1(37)$ & $14.6(15)$ & $28.5(50)$ & $<0.00001$ & 27.4 (349) \\
\hline E. granulosus ${ }^{\mathrm{a}}$ & $8.3(3)$ & $18.2(24)$ & $9.6(9)$ & $12.3(10)$ & $41.3(162)$ & $17.8(23)$ & $27.6(35)$ & $14.6(15)$ & $26.8(47)$ & $<0.00001$ & $25.8(328)$ \\
\hline Trichuris spp. & $52.8(19)$ & $0.7(1)$ & $20(19)$ & $16(13)$ & $0(0)$ & $2.3(3)$ & $3.1(4)$ & $0(0)$ & $1.1(2)$ & $<0.00001$ & $4.8(61)$ \\
\hline Ancylostoma spp. & $5.5(2)$ & $6.8(9)$ & $4.2(4)$ & $8.6(7)$ & $3.7(14)$ & $5.4(7)$ & $5.5(7)$ & $8.7(9)$ & $0(0)$ & 0.0193 & $4.6(59)$ \\
\hline Capillaria spp. & $0(0)$ & $0(0)$ & $0(0)$ & $0(0)$ & $0(0)$ & $0.8(1)$ & $0(0)$ & $0(0)$ & $0(0)$ & 0.3549 & $0.1(1)$ \\
\hline Spirocerca spp. & $5.5(2)$ & $0(0)$ & $1(1)$ & $0(0)$ & $0(0)$ & $0(0)$ & $0(0)$ & $0(0)$ & $0(0)$ & 0.0013 & $0.2(3)$ \\
\hline D. caninum & $0(0)$ & $0.7(1)$ & $0(0)$ & $0(0)$ & $0(0)$ & $0(0)$ & $0(0)$ & $0(0)$ & $0(0)$ & 0.3746 & $0.1(1)$ \\
\hline Coccidia & $38.9(14)$ & $24.2(32)$ & $26.3(25)$ & $4.9(4)$ & $15.5(61)$ & $10.1(13)$ & $8.7(11)$ & $0.9(1)$ & $2.8(5)$ & $<0.00001$ & 13.1 (166) \\
\hline
\end{tabular}

${ }^{a} E$. granulosus eggs were identified on biomolecular basis

Abbreviations: $N$ Number of faecal samples analysed, $n$ Number of positive samples, $\%$ Percentage of positive samples 


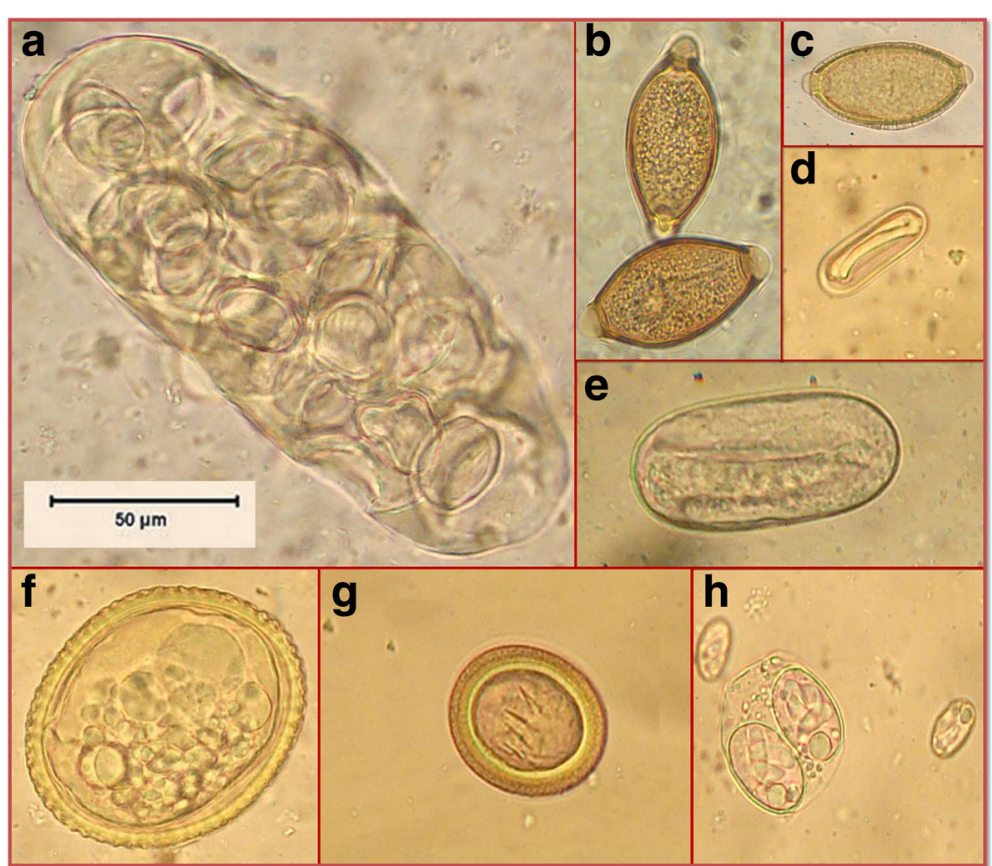

Fig. 2 Cestode and nematode eggs and oocysts observed in the canid faecal samples. a D. caninum egg-capsule. b Trichuris spp. c Capillaria spp. d Spirocerca spp. e Ancylostoma spp. f Toxocara spp. g Taeniidae. h Coccidian oocysts

and Toxocara spp. isolates were ubiquitous even in high temperature regions (Fig. 3, Axis 1).

\section{Discussion}

Although data on the regional prevalence of parasites are crucial to implement strategies for control and treatment, information about parasite environmental contamination is very limited in Tunisia. Except for cystic echinococcosis, epidemiological studies of zoonotic helminths are rare and only few human case reports have been published. Significant levels of

Table 2 Intestinal parasites in canids based on eggs and oocysts recovered in the faeces from Djerba-Zarzis regions

\begin{tabular}{|c|c|c|c|c|}
\hline & $\begin{array}{l}\text { Dogs } \\
(N=256)\end{array}$ & $\begin{array}{l}\text { Wild canids } \\
(N=104)\end{array}$ & Dogs vs wild canids & \\
\hline & $\%(n)$ & $\%(n)$ & Chi-square test & $P$-value \\
\hline Toxocara spp. & $34.3(88)$ & $16.3(17)$ & 11.63 & 0.0006 \\
\hline Taeniidae & $23.4(60)$ & $0(0)$ & 29.25 & $<0.0001$ \\
\hline E. granulosus ${ }^{\mathrm{a}}$ & $22.6(58)$ & $0(0)$ & 28.95 & $<0.0001$ \\
\hline Ancylostoma spp. & $5.4(14)$ & $3.8(4)$ & 0.41 & 0.5219 \\
\hline Trichuris spp. & $2.7(7)$ & $6.3(7)$ & 3.16 & 0.0754 \\
\hline Capillaria spp. & $0.4(1)$ & $9.6(10)$ & 21.25 & $<0.0001$ \\
\hline Spirocerca spp. & $0(0)$ & $1.9(2)$ & 4.95 & 0.0260 \\
\hline Coccidia & $9.3(24)$ & $7.7(8)$ & 0.25 & 0.6108 \\
\hline
\end{tabular}

${ }^{a} E$. granulosus eggs were identified on biomolecular basis Abbreviations: $N$ Number of faecal samples analysed, $n$ Number of positive samples, \% Percentage of positive samples parasitism were observed more in dogs (55\%) than in wild canids $(46.1 \%)$. These contamination levels are comparable to those described for dog faecal samples in other countries such as Cuba (44.3\%) [27], Canada (33.9\%) [28] and Portugal (59.8\%) [29]. To our knowledge, we cannot exclude that the faeces contamination indices were overestimated due to the coprophagic behaviour of canids (consummation of their own faeces, faeces of other canids and/or faeces of other species) [30]. The zoonotic agents Toxocara spp., E. granulosus, Ancylostoma spp. and Trichuris spp. were the most frequent parasites observed in the study. The situation presented here is grossly the same as that in several parts of the world such as Argentina [31], North America [32] or Iran [33]. Helminths encountered in the present study have at least one form infective to humans: the eggs for orally-ingested parasite species, and the free-living stages for skin-penetrating species. The faecal-oral route is the most common way of helminth and protozoan contamination. Thus, the consumption of uncooked vegetables irrigated by water polluted by animal faeces and/or soil ingestion could have a direct impact on human health and cause severe zoonoses [34, 35].

Contrary to previous studies that reported a high $D$. caninum prevalence in necropsied Tunisian dogs (43.6\%) and wild canids (29\%) [21, 22], only one dog positive sample was observed in our study. The results could be explained by an underestimation of copro- 


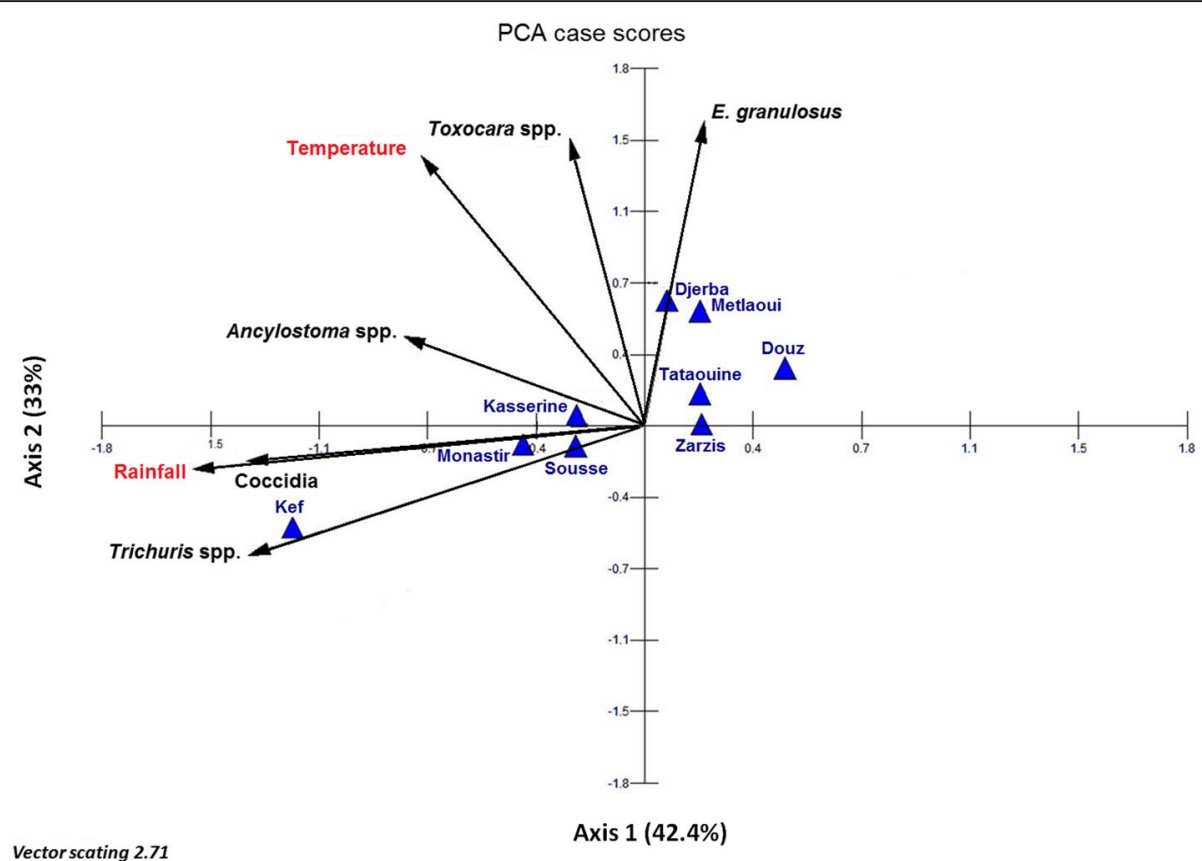

Fig. 3 Parasite contamination indices and Tunisian region bioclimatic characteristics described by principal component analysis. Temperature $\left(\mathrm{C}^{\circ}\right)$ : annual average maximum temperature; Rainfall $(\mathrm{mm})$ : annual average rainfall

helminth prevalence compared to necropsy examination, especially for cestodes, where eggs are mainly intermittently released [28]. Similar results were observed in Nigeria where necropsy of dogs reported a contamination rate of $75 \%$ for D. caninum [36], whereas the direct analysis of faeces revealed a prevalence ranging from 5.7 to $12.3 \%$ [37].

Toxocara spp. are the most common parasites living in the intestines of dogs and wild canids worldwide [38]. Humans are accidental hosts who may become infected by ingesting embryonated eggs through contaminated vegetables/water or by direct contact with dogs $[10,39]$. Human infection may cause severe damage usually involving the back of the eye, the liver, and the lungs [40]. In Tunisia, information about human toxocariasis seroprevalence is nowadays absent because only case reports have been described in the literature [41-46]. In the present study, an important environmental contamination with Toxocara spp. eggs has been demonstrated for dog (all regions) and wild canid (Djerba and Zarzis) faeces, 27.2 and 16.3\% respectively. When infected with $T$. canis, one dog could expel thousands of eggs each day. These eggs are extremely resistant in the environment and could remain infective for 5 years under favorable conditions [47]. Thus, since the environment is seriously contaminated, this zoonosis could result in an important human health problem.

Despite efforts to control the disease, cystic echinococcosis remains a serious public health problem in
Tunisia $[48,49]$. The life-cycle of E. granulosus uses domestic dogs or wild canids as the final host and ungulates as intermediate host. Humans are accidental intermediate hosts and parasite infection from dog to humans may occur, directly by contact with pets or indirectly through contaminated food or soil. In the present study, the occurrence of E. granulosus eggs varied according to the area but no region free of eggs was found. Despite the description of $E$. granulosus tapeworm in red foxes [21] and golden jackals [22] from north-western and central regions of Tunisia, no E. granulosus egg was detected in our wild canid samples although dog faeces contamination was not negligible in the same area (22.6\%). The absence of $E$. granulosus in wild canids might be explained by their lack of opportunity to consume contaminated carcasses of intermediate hosts. However, in the presence of the suitable intermediate hosts in the diets of these animals, E. granulosus was detected in wolves but not in red foxes in Portugal $[13,50]$. Red foxes are rarely infected with E. granulosus, usually with low parasite burdens, and are generally considered of limited importance for cystic echinococcosis transmission [47]. Therefore, it can be assumed that in Tunisia, wild canids are not implied in the disease transmission and that dogs remain the main definitive host in the life-cycle of E. granulosus.

The significant and positive correlation between $E$. granulosus and Toxocara spp. eggs observed in the 
present study, even in arid and desertic environment, is due to their thick outer shell (protein coat) which confers them a resistance to desiccation and to high temperature $\left(30-80{ }^{\circ} \mathrm{C}\right)$ [51-53].

Trichuris spp. is found in domestic and wild canids worldwide. Although it is generally considered as nonzoonotic [54], some human cases of visceral larva migrans due to canid Trichuris species have been described [55-57]. Human infection is due to the accidental ingestion of embryonated eggs. Trichuris spp. was more geographically restricted than the other parasites found in this study and the prevalence of this parasite varied considerably $(0-52.8 \%)$ from one region to another in function of the climate. Thus, in the subhumid area (Kef), the environment is seriously contaminated $(52.8 \%)$ whereas in the semi-arid neighbouring region (Kasserine) the contamination index was very low $(0.7 \%)$. In the desertic and arid regions (Tataouine, Douz and Metlaoui) this parasite was totally absent. A previous study conducted in the Tunisian sub-humid region, reported similar result with a prevalence of $33 \%$ for $T$. vulpis in wild canids [22]. Precipitation and soil humidity are required for maintaining the parasite viability and Trichuris spp. eggs are less likely to survive in drier and sunnier locations and are unlikely to embryonate [52].

Capillaria spp. has a direct life-cycle that requires only one host. Adult worms invade the lungs of domestic and wild canids but may also be found in other mammals including humans [47]. Capillaria spp. was the second parasite most frequently encountered in the wild canid faeces $(9.6 \%)$ and had a limited presence in dog faeces $(0.1 \%)$. Similar results were described in Europe with an occurrence of $0-0.7 \%$ and $60.3-93.8 \%$ for dogs and foxes, respectively [58-60]. Thus, Capillaria spp. seems to be restricted to wildlife due to host-parasite interactions and dietary habits. In Tunisia, it can be assumed that wild canids act as a reservoir for capillariasis and could be responsible for the transmission of Capillaria populations to dogs.

\section{Conclusion}

To our knowledge, the results of this study highlight, for the first time in Tunisia, the environmental contamination by numerous gastrointestinal parasites. In Tunisia, people's awareness regarding zoonotic diseases transmitted by dogs is insufficient. The transmission of gastrointestinal helminths is enhanced by a high stray or semi-stray dog population, inadequate deworming treatment, the close contact of untreated dogs with humans and the favourable climatic conditions for the survival of infective stages outside the hosts. Thus, efforts should be made to increase the awareness of the presence of parasites in the environment and to implement a targeted educational program especially for the dog owners.
Abbreviations

Cl: Confidence interval; PCA: Principal components analysis

\section{Acknowledgements}

The authors are grateful to Pr. Jacques Cabaret (UMR 1282, ISP INRA and F. Rabelais University, Nouzilly, France) and to Pr. Franck Boué (Anses, National Reference Laboratory for Echinococcus spp., Nancy, France) for critically reading the manuscript. The authors also wish to thank Nedra Kerkeni (Higher Institute of Biotechnology of Monastir, Tunisia) for her assistance with the linguistic part of this paper. The authors thank Mohamed Mourad Chaabane for his technical help for the Fig. 1 design.

\section{Funding}

This study was funded by the Tunisian Ministry of Higher Education and Scientific Research. The funding source is not involved in the study design, in the collection, analysis and interpretation of data, in the writing of the report, and in the decision to submit the article for publication.

\section{Availability of data and materials}

The data supporting the conclusions of this article are included within the article. Raw data are available from the corresponding authors on reasonable request.

\section{Authors' contributions}

MOM: participated in the design of the study, contributed to the acquisition of data collection, and have been involved in drafting the manuscript. RCB: contributed to the data collection, carried out the molecular genetic studies and have been involved in drafting the manuscript. SM: participated in the coordination of the study, data collection and revised critically the manuscript for important intellectual content. FT: was involved in the statistical analysis and has critically revised the manuscript. HM: participated in carying out the molecular genetic studies. HB: participated in the design of the study and was involved in critically revising the manuscript. All authors read and approved the final manuscript.

\section{Competing interests}

The authors declare that they have no competing interests.

Consent for publication

Not applicable.

Ethics approval and consent to participate

Not applicable.

\section{Publisher's Note}

Springer Nature remains neutral with regard to jurisdictional claims in published maps and institutional affiliations.

\section{Author details}

${ }^{1}$ Laboratory of Medical and Molecular Parasitology-Mycology (LP3M), LR 12ES08. Faculty of Pharmacy, University of Monastir, 5000 Monastir, Tunisia. ${ }^{2}$ Laboratory of Biomass Valorisation and Production of Eukaryotic Proteins, Center of Biotechnology, University of Sfax, 3018 Sfax, Tunisia. ${ }^{3}$ Laboratory of Parasitology-Mycology, EPS F. Bourguiba, 5000 Monastir, Tunisia.

Received: 15 February 2017 Accepted: 18 May 2017

Published online: 05 June 2017

\section{References}

1. Taye B, Alemayehu B, Birhanu A, Desta K, Addisu S, Petros B, et al. Podoconiosis and soil-transmitted helminths (STHs): double burden of neglected tropical diseases in Wolaita zone, rural Southern Ethiopia. PLoS Negl Trop Dis. 2013;7(3):e2128.

2. Harrington $H$, Bradbury $R$, Taeka J, Asugeni J, Asugeni $V$, Igeni T, et al. Prevalence of soil-transmitted helminths in remote villages in East Kwaio, Solomon Islands. Western Pac Surveill Response J. 2015;6(3):51-8.

3. Ng'etich Al, Rawago FO, Jura WG, Mwinzi PN, Won KY, Odiere MR. A cross-sectional study on schistosomiasis and soil-transmitted helminths in Mbita district, western Kenya using different copromicroscopic techniques. Parasit Vectors. 2016;9:87.

4. Ayeh-Kumi PF, Addo-Osafo K, Attah SK, Tetteh-Quarcoo PB, Obeng-Nkrumah N, Awuah-Mensah G, et al. Malaria, helminths and 
malnutrition: a cross-sectional survey of school children in the South-Tongu district of Ghana. BMC Res Notes. 2016;9:242.

5. Kunwar R, Acharya L, Karki S. Trends in prevalence of soil-transmitted helminth and major intestinal protozoan infections among school-aged children in Nepal. Trop Med Int Health. 2016;21(6):703-19.

6. Macpherson CN. Human behaviour and the epidemiology of parasitic zoonoses. Int J Parasitol. 2005;35(11-12):1319-31.

7. Papazahariadou M, Founta A, Papadopoulos E, Chliounakis S, Antoniadou-Sotiriadou K, Theodorides Y. Gastrointestinal parasites of shepherd and hunting dogs in the Serres Prefecture, northern Greece. Vet Parasitol. 2007;148(2):170-3.

8. Bentounsi B, Meradi S, Ayachi A, Cabaret J. Cestodes of untreated large stray dog populations in Algeria: A reservoir for herbivore and human parasitic diseases. Open Vet Sci J. 2009;3:64-7.

9. Dakkak A. Echinococcosis/hydatidosis: a severe threat in Mediterranean countries. Vet Parasitol. 2010;174(1-2):2-11.

10. Overgaauw PA, van Knapen F. Veterinary and public health aspects of Toxocara spp. Vet Parasitol. 2013;193(4):398-403.

11. Alvarez Rojas CA, Romig T, Lightowlers MW. Echinococcus granulosus sensu lato genotypes infecting humans- review of current knowledge. Int J Parasitol. 2014:44(1):9-18.

12. Elmore SA, Lalonde LF, Samelius G, Alisauskas RT, Gajadhar AA, Jenkins EJ. Endoparasites in the feces of arctic foxes in a terrestrial ecosystem in Canada. Int J Parasitol Parasites Wildl. 2013;2:90-6.

13. Guerra D, Armua-Fernandez MT, Silva M, Bravo I, Santos N, Deplazes P, et al. Taeniid species of the Iberian wolf (Canis lupus signatus) in Portugal with special focus on Echinococcus spp. Int J Parasitol Parasites Wildl. 2013:2:50-3.

14. Duscher GG, Leschnik M, Fuehrer HP, Joachim A. Wildlife reservoirs for vector-borne canine, feline and zoonotic infections in Austria. Int J Parasitol Parasites Wildl. 2015;4(1):88-96.

15. Lee AC, Montgomery SP, Theis JH, Blagburn BL, Eberhard ML. Public health issues concerning the widespread distribution of canine heartworm disease. Trends Parasitol. 2010;26(4):168-73.

16. Alelign T, Degarege A, Erko B. Soil-transmitted helminth infections and associated risk factors among schoolchildren in Durbete Town, northwestern Ethiopia. J Parasitol Res. 2015. doi:10.1155/2015/641602.

17. Doni NY, Gürses G, Simssek Z, Zeyrek FY. Prevalence and associated risk factors of intestinal parasites among children of farm workers in the southeastern Anatolian region of Turkey. Ann Agric Environ Med. 2015; 22(3):438-42

18. Aoun K, Bouratbine A. Epidemiological data concerning hydatidosis in Tunisia. Med Mal Infect. 2007;37:S40-2.

19. Lahmar S, Kilani M, Torgerson PR. Frequency distributions of Echinococcus granulosus and other helminths in stray dogs in Tunisia. Ann Trop Med Parasitol. 2001;95(1):69-76.

20. Lahmar S, Sarciron ME, Rouiss M, Hammouda A, Youssfi M, Mensi M. Echinococcus granulosus and other intestinal helminths in semi-stray dogs in Tunisia: infection and re-infection rates. Tunis Med. 2008:86(3): 279-86.

21. Lahmar S, Boufana BS, Lahmar S, Inoubli S, Guadraoui M, Dhibi M, et al. Echinococcus in the wild carnivores and stray dogs of northern Tunisia: the results of a pilot survey. Ann Trop Med Parasitol. 2009;103(4):323-31.

22. Lahmar S, Boufana B, Ben Boubaker S, Landolsi F. Intestinal helminths of golden jackals and red foxes from Tunisia. Vet Parasitol. 2014;204(3-4): 297-303.

23. Chaabane-Banaoues R, Oudni-M'rad M, Cabaret J, M'rad S, Mezhoud H, Babba H. Infection of dogs with Echinococcus granulosus: causes and consequences in an hyperendemic area. Parasit Vectors. 2015;8:231.

24. Dryden MW, Payne PA, Ridley R, Smith V. Comparison of common fecal flotation techniques for the recovery of parasite eggs and oocysts. Vet Ther. 2005;6(1):15-28.

25. Mehlhorn H. Encyclopedia of Parasitology. 3rd ed. Berlin: Springer; 2008.

26. Sambrook J, Fitsch EF, Maniatis T. Molecular Cloning: A Laboratory Manual. 2nd ed. New York: Cold Spring Harbor, Laboratory Press; 1989.

27. Puebla LEJ, Nunez FA, Rivero LR, Hernandez YR, Garcia IS, Millan IA. Prevalence of intestinal parasites in dogs from municipality La Lisa, Havana, Cuba. J Vet Sci Technol. 2015:6:5.

28. Villeneuve A, Polley L, Jenkins E, Schurer J, Gilleard J, Kutz S, et al. Parasite prevalence in fecal samples from shelter dogs and cats across the Canadian provinces. Parasit Vectors. 2015;8:281.
29. Mateus TL, Castro A, Ribeiro JN, Vieira-Pinto M. Multiple zoonotic parasites identified in dog feces collected in Ponte de Lima, Portugal - a potential threat to human health. Int J Environ Res Public Health. 2014;11(9):9050-67.

30. Nijsse R, Mughini-Gras L, Wagenaar JA, Ploeger HW. Coprophagy in dogs interferes in the diagnosis of parasitic infections by faecal examination. Vet Parasitol. 2014;204(3-4):304-9.

31. Soriano SV, Pierangeli NB, Roccia I, Bergagna HF, Lazzarini LE, Celescinco A, et al. A wide diversity of zoonotic intestinal parasites infects urban and rural dogs in Neuquen, Patagonia, Argentina. Vet Parasitol. 2010;167(1):81-5.

32. Bridger KE, Whitney $H$. Gastrointestinal parasites in dogs from the Island of St. Pierre off the south coast of Newfoundland. Vet Parasitol. 2009; 162(1-2):167-70.

33. Beiromvand M, Akhlaghi L, Fattahi Massom SH, Meamar AR, Motevalian A Oormazdi $\mathrm{H}$, et al. Prevalence of zoonotic intestinal parasites in domestic and stray dogs in a rural area of Iran. Prev Vet Med. 2013;109(1-2):162-7.

34. Thompson RC, Smith A. Zoonotic enteric protozoa. Vet Parasitol. 2011; 182(1):70-8

35. Adanir R, Tasci F. Prevalence of helminth eggs in raw vegetables consumed in Burdur, Turkey. Food Control. 2013;31(2):482-4.

36. Umar YA. Intestinal helminthoses in dogs in Kaduna Metropolis, Kaduna State, Nigeria. Iran J Parasitol. 2009;4(1):34-9.

37. Ugbomoiko US, Ariza L, Heukelbach J. Parasites of importance for human health in Nigerian dogs: high prevalence and limited knowledge of pet owners. BMC Vet Res. 2008:4:49.

38. Macpherson CNL. The epidemiology and public health importance of toxocariasis: A zoonosis of global importance. Int J Parasitol. 2013;43(12-13): 999-1008.

39. El-Tras WF, Holt HR, Tayel AA. Risk of Toxocara canis eggs in stray and domestic dog hair in Egypt. Vet Parasitol. 2011;178(3-4):319-23.

40. Fan CK, Liao CW, Cheng YC. Factors affecting disease manifestation of toxocarosis in humans: genetics and environment. Vet Parasitol. 2013;193(4): $342-52$

41. Arfaoui B, Boussetta N, Abid R, Sayhi S, Batikh R, Ben Abdelhafidh N, et al. Toxocarose viscérale chez l'adulte, à propos de 2 cas. Rev Med Interne. 2015;36 Suppl 2:A116-7

42. Hamrouni S, Boussetta N, Dhahri R, Sayhi S, Gharsallah I, Metoui L, Suppl 2. Toxocarose oculaire: à propos de trois cas. Rev Med Interne. 2015;36:A116.

43. Lajmi M, Boussetta N, Sayhi S, Dhahri R, Abid R, Batikh R, Suppl 2. Une parasitose rare: la toxocarose (à propos de 5 cas). Rev Med Interne. 2015; 36:A118.

44. Mrissa M, Battikh R, Ben Abdelhafidh N, Jemli B, Azzouz O, Zaouali J, et al. Toxocara canis encephalitis: case report. Rev Med Interne. 2005;26(10): 829-32.

45. Taheri O, Blaison G, Sawaf K, Potelon P, De Briel D, Martinot M, Suppl 2. Toxocarose révélée par des nodules pulmonaires excavés et une hyperéosinophilie chez une patiente présentant des douleurs mammaires atypiques. Rev Med Interne. 2015:36:A117.

46. Trabelsi H, Neji S, Cheikhrouhou F, Sellami H, Guidara R, Mhiri W, et al, Ocular toxocariasis: a case report. J Fr Ophtalmol. 2014;37(6):e81-2.

47. Otranto D, Cantacessi C, Dantas-Torres F, Brianti E, Pfeffer M, Genchi C, et al. The role of wild canids and felids in spreading parasites to dogs and cats in Europe. Part II: Helminths and arthropods. Vet Parasitol. 2015; 213(1-2):24-37.

48. Chahed MK, Bellali H, Touini H, Cherif R, Ben Safta Z, Essoussi M, et al. L'incidence chirurgicale du kyste hydatique en Tunisie : résultats de l'enquête 2001-2005 et tendance évolutive entre 1977-2005. Arch Inst Pasteur Tunis. 2010;87(1-2):43-52.

49. Oudni-M'rad M, M'rad S, Babba H. Molecular and epidemiology data on cystic echinococcosis in Tunisia. In: Rodriguez-Morales AJ, editor. Current topics in echinococcosis. Rijeka: InTech; 2015. p. 56-74.

50. Eira C, Vingada J, Torres J, Miquel J. The helminth community of the red fox Vulpes vulpes, in Dunas de Mira (Portugal) and its effect on host condition. Wildl Biol Pract. 2006;2(1):26-36.

51. Thevenet PS, Jensen O, Drut R, Cerrone GE, Grenovero MS, Alvarez HM, et al. Viability and infectiousness of eggs of Echinococcus granulosus aged under natural conditions of inferior arid climate. Vet Parasitol. 2005;133(1):71-7.

52. Maya C, Torner-Morales FJ, Lucario ES, Hernández E, Jiménez B. Viability of six species of larval and non-larval helminth eggs for different conditions of temperature, pH and dryness. Water Res. 2012;46(15):4770-82.

53. Tarbiat $B$, Jansson DS, Hoglund J. Environmental tolerance of free-living stages of the poultry roundworm Ascaridia galli. Vet Parasitol. 2015;209(1-2):101-7. 
54. Traversa D. Are we paying too much attention to cardio-pulmonary nematodes and neglecting old-fashioned worms like Trichuris vulpis? Parasit Vectors. 2011;4:32.

55. Areekul P, Putaporntip C, Pattanawong U, Sitthicharoenchai P, Jongwutiwes S. Trichuris vulpis and T. trichiura infections among schoolchildren of a rural community in northwestern Thailand: the possible role of dogs in disease transmission. Asian Biomed. 2010;4(1):49-60.

56. Dunn JJ, Columbus ST, Aldeen WE, Davis M, Carroll KC. Trichuris vulpis recovered from a patient with chronic diarrhea and five dogs. J Clin Microbiol. 2002;40(7):2703-4.

57. Marquez-Navarro A, Garcia-Bracamontes G, Alvarez-Fernandez BE, Avila-Caballero LP, Santos-Aranda I, Diaz-Chiguer DL, et al. Trichuris vulpis (Froelich, 1789) infection in a child: a case report. Korean J Parasitol. 2012; 50(1):69-71

58. Hauser M, Basso W, Deplazes P. Dog and fox faecal contamination of farmland. Schweiz Arch Tierheilkd. 2015;157(8):449-55.

59. Al-Sabi MN, Kapel CM, Johansson A, Espersen MC, Koch J, Willesen JL. A coprological investigation of gastrointestinal and cardiopulmonary parasites in hunting dogs in Denmark. Vet Parasitol. 2013;196(3-4):366-72.

60. Al-Sabi MN, Halasa T, Kapel CM. Infections with cardiopulmonary and intestinal helminths and sarcoptic mange in red foxes from two different localities in Denmark. Acta Parasitol. 2014:59(1):98-107.

Submit your next manuscript to BioMed Central and we will help you at every step:

- We accept pre-submission inquiries

- Our selector tool helps you to find the most relevant journal

- We provide round the clock customer support

- Convenient online submission

- Thorough peer review

- Inclusion in PubMed and all major indexing services

- Maximum visibility for your research

Submit your manuscript at www.biomedcentral.com/submit
Biomed Central 